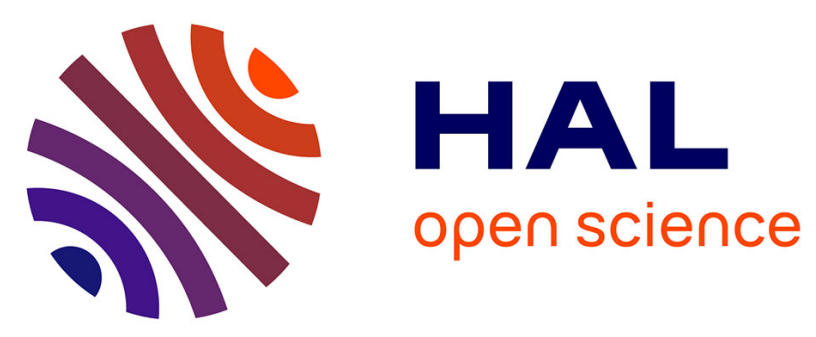

\title{
STUDIES OF NEW RADIOACTIVE NUCLEI AT GANIL ENERGIES
}

\author{
F. Hubert, J. Dufour, R. del Moral, H. Emmermann, D. Jean, C. Poinot, M. \\ Pravikoff, Agnès Fleury, H. Delagrange, H. Geissel, et al.
}

\section{To cite this version:}

F. Hubert, J. Dufour, R. del Moral, H. Emmermann, D. Jean, et al.. STUDIES OF NEW RADIOACTIVE NUCLEI AT GANIL ENERGIES. International Conference On Heavy Ion Nuclear Collisions In The Fermi Energy Domain,Hicofed 86, 1986, Caen, France. pp.C4-229-C4-240, 10.1051/jphyscol:1986427 . jpa-00225793

\section{HAL Id: jpa-00225793 https://hal.science/jpa-00225793}

Submitted on 1 Jan 1986

HAL is a multi-disciplinary open access archive for the deposit and dissemination of scientific research documents, whether they are published or not. The documents may come from teaching and research institutions in France or abroad, or from public or private research centers.
L'archive ouverte pluridisciplinaire HAL, est destinée au dépôt et à la diffusion de documents scientifiques de niveau recherche, publiés ou non, émanant des établissements d'enseignement et de recherche français ou étrangers, des laboratoires publics ou privés. 


\section{STUDIES OF NEW RADIOACTIVE NUCLEI AT GANIL ENERGIES ${ }^{(1)}$}

F. HUBERT, J.P. DUFOUR, R. DEL MORAL, H. EMMERMANN, D. JEAN,

C. POINOT, M.S. PRAVIKOFF, A. FLEURY, H. DELAGRANGE*,

H. GEISSEL * and K.-H. SCHMIDT ${ }^{*}$ *

Centre d'Etudes Nucléaires de Bordeaux-Gradignan, Le Haut Vigneau, F-33170 Gradignan, France

* GANIL, BP 5027, F-14021 Caen Cedex, France

" "Gesellschaft für Schwerionenforschung, D-6100 Darmstadt, F.R.G.

Résumé - Des études de radioactivitē $\beta-\gamma$ de noyaux exotiques légers riches en neutrons ont été réalisêes sur la ligne LISE à GANIL. Ces isotopes ont été produits par fragmentation des ions ${ }^{40} \mathrm{Ar}$ de $60 \mathrm{MeV} / \mathrm{nucléon}$ sur une cible de Be. L'association d'un dégradeur convenablement profilé à la séparation magnẻtique classique, permet d'isoler spatialement les isotopes formés. Au moins 9 isotopes ont été observés pour la première fois par des mesures de coincidence $\beta-\gamma$. Les résultats obtenus sont comparés aux prédictions données par différents modèles.

Abstract - Radioactive studies of light neutron rich exotic nuclei from ${ }^{17} \mathrm{C}$ to ${ }^{40} \mathrm{~S}$ have been performed on the LISE line at GANIL. These isotopes were produced via projectile fragmentation of $60 \mathrm{MeV} /$ nucleon ${ }^{40} \mathrm{Ar}$ on Be. The adjunction of an energy degrader with appropriate shape is shown to allow the use of the LISE spectrometer for a projectile fragment isotopic separation. At least 9 nuclei were observed for the first time through $\beta-\gamma$ coincidence measurements. The predictive power of different models for $\beta$ decay properties is examined.

\section{I - INTRODUCTION}

In order to study the radioactive properties of exotic species, one needs firstly to produce these nuclei with the high rates compatible with $\beta, \gamma, p, \alpha$ or $n$ spectroscopies and secondly to have them separated from the variety of isotopes present at the same time. In the GANIL energy domain, the projectile fragmentation mechanism has been successfully used to produce exotic nuclei $/ 1-4 /$. As far as total production rates are concerned, this method seemed not too favorable at first sight. Indeed compared to the widely used target fragmentation mechanism induced by relativistic light particles the available beam intensities and the thicknesses of targets are much lower in the former case. But, the kinematical properties of forward focussing of the projectile fragmentation allow the separation of elements not accessible to classical ion sources. Among all methods used to separate radioactive nuclei, magnetic analysis combined with detection into a focal plane detector system is particularly powerful for identifying projectile fragments, as it was firstly shown with relativistic heavy ions /5-7/ In this case, the selected nuclei are then electronically identified from a mixture of isotopes. The magnetic spectrometer IISE at GANIL /8/ and the reaction product mass separator (RPMS) at MSU /9/ designed for the study of exotic nuclei allow such a separation method. Thus a large number of new isotopes lying as wel1 on the neutron as on the proton rich side have been identified at LISE using time of flight plus $\Delta \mathrm{E} \times \mathrm{E}$ measurements $/ 1,2,4 /$. At the RPMS new $\beta$ deeay half iives have been measured for light neu-

(1) Experiment performed at the GANIL National Laboratory in Caen. France 
tron rich isotopes $/ 10 /$. In this last case, the stopping solid state detector is simu1taneously used as heavy ion and $B$ detector. The position sensitivity allow a correlation to be made between the position of the incident fragment and the decay electron.

A new technique has been developed on LISE by our group in order to get an almost complete mass and charge separation $/ 11 /$. In the case of gamma spectroscopy one cannot rely on an electronic identification to associate unambiguously the decay properties with a given $(A, Z)$ nuclide and a physical separation is highly desirable. The adjonction of an intermediate degrader between the two dipoles of the LISE spectrometer allows to select a few nuclides or a given ( $A, Z$ ) fragment depending on the specific case. Neutron rich nuclei produced in the fragmentation of ${ }^{40} \mathrm{Ar}(60 \mathrm{~A} . \mathrm{MeV})$ have then been separated and $\beta-\gamma$ spectroscopy has been carried on for the first time for several cases. Part of the experimental results have been obtained at CERN using a transport beam line as a crude approximation of LISE $/ 12,13 /$.

In the following, section 2 presents the projectile fragment isotopic separation method and the calculated selection properties of the LISE line. Then the new radioactive decay properties of the studied nuclei from ${ }^{17} \mathrm{C}$ to ${ }^{40} \mathrm{~S}$ are given in section 3 .

II - THE PROJECTILE FRAGMENT ISOTOPIC SEPARATION (PFIS) METHOD

\section{II-1 Experimental set-up}

The experimental device for which the analysis has been developed is the spectrometer LISE which is a system consisting essentially of two identical dipoles $D_{1}$ and $D_{2}$ as schematically shown in fig. 1. In the focal plane of the first dipole, adjustable

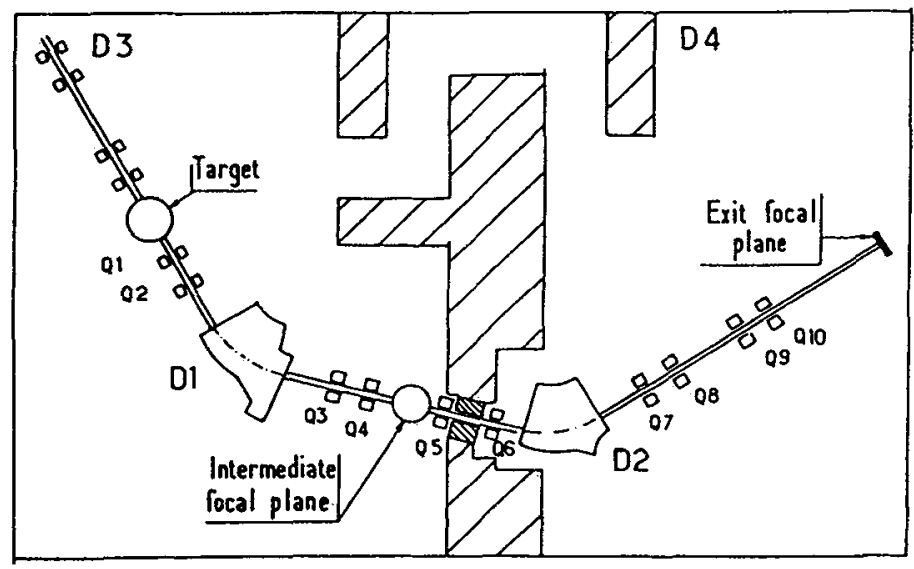

Fig. 1 : Schematic drawing of the LISE spectrometer at GANIL

slits allow one to limit the magnetic rigidity acceptance of the line. For the PFIS method, an energy degrader made of an aluminium wedge with a thickness ranging from $200 \mu$ and $1400 \mu$ was placed behind the slits. After transmission through the second dipole the selected projectile fragments (PF) entered the counting area (see fig. 2). These fragments were discriminated according to their total ranges in Al using a set of foils placed 1 meter ahead of the detectors. Finally the selected nuclei were stopped in a catcher tape surrounded by a beta plastic scintillator and an ultra pure high efficiency, high resolution intrinsic Ge gama detector. 


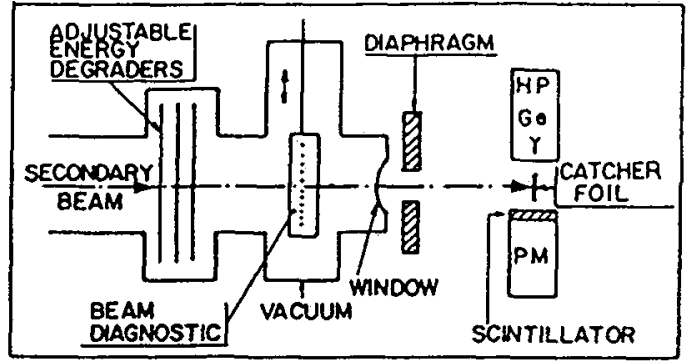

Fig. 2 : Sketch of the experimental set-up allowing the range selection and the study of gamma spectroscopy in coincidence with beta decays

\section{II-2 Principe of the method}

The method used to separate a definite nucleus of atomic charge $Z$ and atomic mass $A$ consists in the following steps :

i) If one assumes that the projectile fragmentation mechanism is velocity conserving, the first dipole provides a selection according to the ratio $r_{1}=A / Z$ since

$$
B p_{1}=0.1439(\mathrm{~A} / \mathrm{Z}) \sqrt{\mathrm{E} / \mathrm{A}}
$$

where $\mathrm{E}$ is the energy in $\mathrm{MeV}$ of the $(A, Z)$ ion, and $\mathrm{B} \rho$, the magnetic rigidity in $\mathrm{T} . \mathrm{m}$.

ii) After the first dipole, the selected ions undergo a slowing-down in a thick degrader and lose momentum differentially according to their $A$ and $Z$. This momentum loss is exploited by the second dipole to provide a second separation inside the subset of nuclei having $A / Z$ constant. The characteristic property of this second selection is derived from a simple empirical relationship (obtained by fitting the range energy tables of Hubert et al./14/ in the GANIL energy domain) giving the range $R$ of a $(A, Z)$ nucleus having an energy $E$ :

$$
R \simeq K\left(A / z^{2}\right)(E / A)^{\lambda / 2}
$$

$\mathrm{K}$ and $\lambda$ being constants depending on the stopping material only. The interest of this expression is that firstly it gives a simple formula for the energy $E_{d}$ of the ions at the exit of a degrader :

$$
E_{d} / E=(1-d / R)^{2 / \lambda}
$$

d being the thickness of the degrader. Secondly, combining relations (1) and (2) one can express the range as a function of $\mathrm{A}, \mathrm{Z}$ and $\mathrm{BO}, \mathrm{O}$ only :

$$
\mathrm{R}_{1}=\mathrm{K}^{\prime}\left(\mathrm{z}^{\lambda-2} / \mathrm{A}^{\lambda-1}\right) \mathrm{B} \rho_{1}^{\lambda}
$$

It follows that the magnetic rigidity $\mathrm{Bp}_{2}$ of the second dipole, may be expressed as a function of $\mathrm{d}$ and $\mathrm{BP}$, only :

$$
\mathrm{B}_{2}=\mathrm{B} \rho_{1}\left(1-\mathrm{d} / \mathrm{R}_{1}\right)^{1 / \lambda}
$$

For a given $\mathrm{B} \rho_{1}$ value, the ions not discriminated by $\mathrm{B} \rho_{2}$ are those having the same range i.e. the same value of the ratio $r_{2}=A^{\lambda-1} / 2^{\lambda-2}$ as shown by eq. (4). Using $\lambda=3.50$, the value for an aluminium degrader, this ratio may be written as $r_{2}=A^{2.5} / z^{1.5}$. The second dipole provides thus a selection according to the ratio $r_{2}$. 


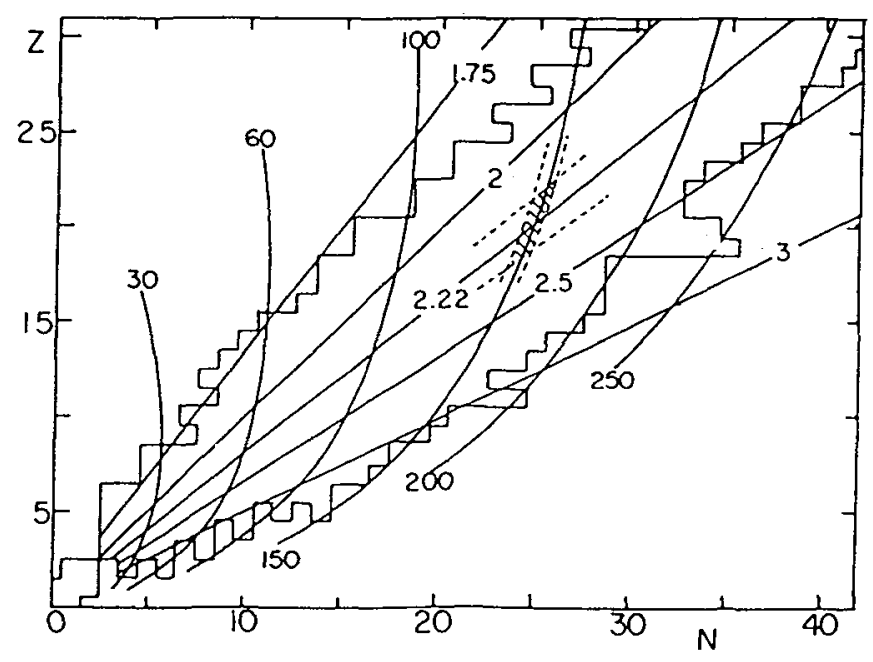

Fig. 3 : The two selections of the PFIS method in the (N, Z) plane

The remarkable feature of these 2 selections characterized by $r_{1}$ and $r_{2}$ respectively is that they depend neither on the beam energy and nature (in the intermediate energy range) nor on the tuning of the line or on the degrader thickness. In fig. 3 representing a part of the chart of nuclides is shown how these 2 selections work. The ions selected by the first dipole are located on the straight lines corresponding to several $\mathrm{A} / \mathrm{Z}$ ratios (represented from 1.75 to 3 ). The ions selected by the second dipole are located on the curves corresponding to several $A^{2.5} / Z^{1.5}$ ratio (represented from 30 to 250). Each selection has a given width. in the (N, Z) plane locally represented by the dotted lines and the nuclei transmitted by the spectrometer are located in a $(N, Z$ ) domain such as represented by the lightly hatched area. The separation of any produced $(A, Z)$ nucleus is realized by a correct tuning of the 2 dipoles according to the following relations (obtained when combining eqs. (1) to (5)) :

$$
\begin{aligned}
& A=K_{1}\left(B \rho_{1}^{\lambda}-B \rho_{2}^{\lambda}\right) B \rho_{1}^{2-\lambda} / d \\
& Z=K_{2}\left(B \rho_{1}^{\lambda}-B \rho_{2}^{\lambda}\right) \quad B \rho_{1}^{1-\lambda} / d
\end{aligned}
$$

$\mathrm{K}_{1}, \mathrm{~K}_{2}$ and $\lambda$ being constants characterizing the slowing-down process in the material at intermediate energy.

\section{II-3 Selection performances of the line}

\section{II-3-1 Optimum target thickness and transmission yields}

Since the method is intended for exotic nuclei separation, one seeks to use a target as thick as possible to increase the counting rate. An increase of the target thickness enlarges the energy distribution of the PF at the exit and may contribute to an increase of the mass acceptance. Consequently it is of prime importance to determine to which extent the increase in target thickness enhances the counting rate and not only contributes to an increase in the mass acceptance of the system.

In the target two processes broaden the energy spectrum of the PF :

i) the slowing-down process which gives different energy losses for the incident ion and the PF.

ii) the nuclear reaction which induces an almost gaussian dispersion.

These two processes have a maximum effect for PF observed far away from the incident ion. 
II-3-2 Effect of the intermediate degrader : achromatism of the line and mass resolution

The introduction of a thick degrader between the 2 dipoles allows to physically isolate a given $(A, Z)$ nucleus. But one can wonder about the characteristics of the line when using such a degrader. We will see in what follows that the degrader may be $s$ haped in thickness in order to preserve the achromatism of the line. Consequently the emittance of the secondary beam and the image size at the exit are kept at a low level. The particles entering the degrader at the abscissa $x$ (Ox being the horizontal axis in the focal plane and 0 the focal point) have a magnetic rigidity

$B \rho_{1}(x)=B \rho_{1}\left(1+x / D_{1}\right)$ where $D_{1}$ is the dispersion of the first dipole expressed in $\mathrm{cm} / \% \mathrm{~B} \rho$. After the degrader the value $\mathrm{B} \rho_{2}(x)$ is given by eq. (5) where $B \rho_{2}, B \rho_{1}$, $d$ and $R$ are now depending on $x$. The achromatism of the line is conserved if $B \rho_{1}(x)$ and $B \rho_{2}(x)$ are proportional for all $x$ values. This is not true in most general cases. But if the shape $d(x)$ of the degrader is such that $d(x) / R_{1}(x)$ is independent of $x$, the achromatism of the line is conserved. This condition is fulfilled with a wedge-shaped degrader of the following type (deduced from eqs. (4) to (5)) :

$$
\mathrm{d}(\mathrm{x})=\mathrm{d}_{0}\left(1+\frac{\mathrm{x}}{\mathrm{D}_{1}}\right)^{\lambda}
$$

This is a very simple formula where $d_{0}$ is a free scaling parameter equal to the degrader thickness on the optical axis. The most striking result is that the wedge shape allowing to conserve the achromatism of the line is independent of the mass, charge and energy of the studied ions as well as the tuning of the line.

one may calculate the theoretically achievable mass resolution with such a wedge. One finds :

$$
\frac{A}{\Delta A}=\frac{\lambda-1}{\lambda} \quad \frac{d_{0}}{R_{1}} \frac{D_{2}}{\phi_{0}}
$$

where $\mathrm{D}_{2}$ and $\phi_{0}$ represent the dispersion of the second dipole and the nominal image size of the spectrometer before the insertion of the wedge. For the IISE spectrometer using $\mathrm{D}_{2}=2.25 \mathrm{~cm} / \%, \phi_{0} \simeq 4 \mathrm{~mm}, \lambda=3.5$ and $\mathrm{d}_{0} / \mathrm{R}_{1} \simeq 0.5$ (i.e. a degrader thickness equal to half the total range of the ions at the exit of the first dipole) one finds $(A / \Delta A) \cong 200$. In this case the final image becomes $8 \mathrm{~mm}$ wide. From an experimental point of view the resolution measured on ${ }^{37} \mathrm{P}$ formed by fragmentation of $60 \mathrm{~A} \cdot \mathrm{MeV}{ }^{40} \mathrm{Ar}$ is $\sim 100$.

As a conclusion of this paragraph, the preceding analysis gives a precise description of the most suitable geometry of the intermediate wedge-shaped degrader in order to conserve the achromatism of the line and to obtain the maximum mass resolution. Only an upper value of the resolution is obtained. This estimate indicates that the degrader's thickness must be at least half the total range of the ions at the exit of the first dipole when a mass resolution of 200 is desired.

\section{III - STUDIES OF RADIOACTIVE NUCLEI}

Neutron rich nuclei have been produced via the projectile fragmentation of $60 \mathrm{MeV} / \mathrm{nu}-$ cleon ${ }^{40} \mathrm{Ar}$ on a $190 \mathrm{mg} / \mathrm{cm}^{2} \mathrm{Be}$ target. The mean thickness of the A1 intermediate energy degrader was $180 \mathrm{mg} / \mathrm{cm}^{2}$.

As the slowing-down process in thick material is an essential part of the method, the used range-energy relations were first checked. A slight correction was then applied to better describe the experimental ranges. The check of the magnetic rigidity determinations has been done with already known isotopes 1 ike ${ }^{15} \mathrm{C}, 2{ }_{\mathrm{o}},{ }^{25} \mathrm{Ne}$ and ${ }^{30} \mathrm{Mg}$. They were identified by their $Y$ spectrum recorded in coincidence with their $B$ decay, and the measure of their half-1ife which was carried out using pulsed beam. The influence of the $\mathrm{BP}_{2}$ tuning is much more critical than that of $\mathrm{Bp}_{1}$ if one wishes to transmit 
a given isotope. In all cases the maximum counting rate was precisely observed for the "a priori" theoretical values. The A and $Z$ of nuclei with unknown decay properties were then deduced from the measurements of $\mathrm{B} \rho$, and $B \rho_{2}$. The recorded spectrum for the study of a $(A, Z)$ nuclei presents several contaminants. The first ones are those not discriminated by the second selection, $i . e$. nuclei having the saine $r_{2}=A^{2.5} / Z^{1.5}$ ratio: the $(A, Z)$ and $(A+3, Z+2)$ isotopes are always present in the same spectrum. Secondly, the finite resolution of the second selection introduced by the presence of a diaphragm allows the transmission of the $(A+1, Z+1),(A+2, Z+2)$ and $(A-2, Z-1)$ nuclei Finally, the daughters of these nuclei are also observed. But it must be emphasized that a $(A, Z+1)$ nucleus is never directly transmitted by the line if correctly tuned for a $(A, Z)$ nucleus but is present only as a daughter activity. In practice, the pre.. sence of well-known contaminants even with a count-rate comparable to the nucleus of interest is supportable. However the amount of contaminant ions simultaneously transmitted by the second dipole is strongly dependent on $B p_{1}$ and can then be reduced.

Several types of information were obtained in this study :

- the evolution of the activity of each $Y$ ray measured in coincidence with $\beta$ decay in function of time. The measured half-lives are listed in table 1.

- the energy of each $\gamma$ ray, the uncertainty on the energy values being always lower than I keV.

- the relative intensity of each $\gamma$ line. In tables 2-8, they have been normalizec on the most intense Iine. The intensity values have been calculated from an accurate study of the efficiency of the $\gamma$ detector. The absolute errors quoted in the various tables represent statistical uncertainties only.

- it is beyond the scope of this paper to present precise $\beta$ decay schemes of the measured nucleus or level schemes of the daughter nucleus. But using simple considerattions of $\gamma$ energy balance and relative $\gamma$ ray intensities, new information on level ener gies and on the feeding of these levels is presented for some simple cases.

- since long the sd shell nuclei represent an ideal test case to shel1-model calsulations, the number of nucleons being in the right range : i) large enough to allow the mean potential approximation and ii) small enough to limitate the number of individual states to consider in the calculation. For neutron rich nuclei, Wildenthal et al /l5i have calculated total half-lives and decay probabilities to individual daughter states. Recently calculations have been performed by Woods /16/ for level scheme of neutron rich nuclei with $A=35-41$. Comparison of the predictions with experimental results will be presented when it is possible.

\section{III-1 Half-life measurements}

The half-lives measured in this work are listed in table 1 . when they represent a first measurement only. The decay curves of the most prominent observed $\gamma$ rays are presented in fig. 4. For comparison the theoretical predictions given by the gross theory

\begin{tabular}{|c|c|c|c|c|c|}
\hline \multirow[t]{2}{*}{ Isotope } & \multirow{2}{*}{$\begin{array}{c}\text { Measured half-life } \\
\text { (a) } \\
\text { this work }\end{array}$} & \multicolumn{3}{|c|}{ Predicted half-life (s) } & \multirow[b]{2}{*}{ Ref .15} \\
\hline & & Ref.17 & Ref. 18 & Ref 19 & \\
\hline${ }^{40} \mathrm{~s}$ & $7.6 .(25)$ & 30. & 18. & 13.6 & \\
\hline${ }^{38} \mathrm{P}$ & $.70(15)$ & .7 & 1. & .146 & \\
\hline${ }^{37} \mathrm{P}$ & $2.3(2)$ & 4. & 4.4 & .744 & \\
\hline${ }^{36} \mathrm{si}$ & $.40(6)$ & 5. & 3. & .14 & \\
\hline${ }^{35} \mathrm{si}$ & $1.0(3)$ & 2. & 2. & .305 & \\
\hline${ }^{34} \mathrm{Al}$ & $.05(2)$ & .2 & .26 & .076 & \\
\hline${ }^{26} \mathrm{Ne}$ & $<.3$ & 1. & .6 & .043 & .170 \\
\hline${ }^{4} \mathrm{~F}$ & $.34(8)$ & .1 & .14 & .577 & $\begin{array}{r}.171 \\
.321\end{array}$ \\
\hline${ }^{19} \mathrm{~N}$ & $.27(7)$ & .4 & .46 & .591 & \\
\hline
\end{tabular}

Table 1 : Measured and predicted half-lives of new isotopes. Absolute uncertainties are given in parentheses. 


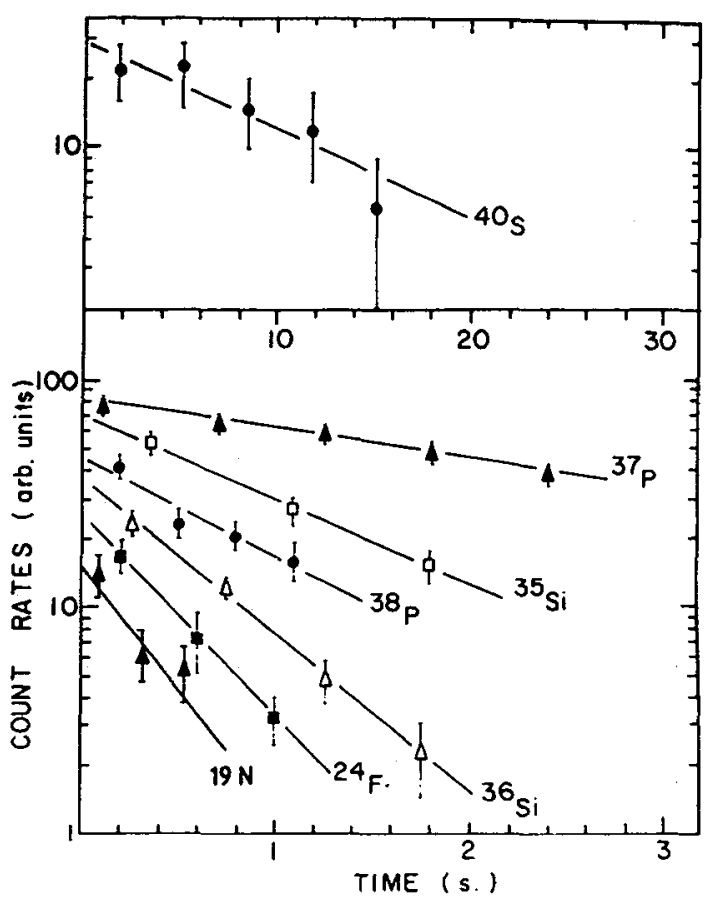

Fig. 4 : The B-decay half-life data from this experiment along with their best fit curves

of nuclear $\beta$ decay $/ 17,18 /$, the calculations of Klapdor et al. $/ 19 /$ and those of Wildenthal et al. $/ 15 /$ are also given in table 1 . On the overall the measured halflives lie between the calculated values. One can notice that the recent modifications of the gross theory of $\beta$ decay give a better agreement when compare to the experimental values for even-even nuclei only. The microscopic calculations ref. 19 certainly are improvements over the gross theory of $\beta$ decay particularly in this transitionnal region with a neutron shel1 closure at $\mathrm{N}=20$. Nevertheless, the reliability of such $a$ model is still limited. With regards to the calculations of ref. 15 for the sd shell nuclei, the agreement with experimental half-life values is quite good.

\section{III-2 $\underline{\beta-\gamma}$ Spectroscopic measurements}

$$
\text { IIII-2-1. } \beta \text { decay of }{ }^{17} \mathrm{C} \text {. }
$$

The $\beta$ decay half-1ife of ${ }^{17} \mathrm{C}$ was recently measured $/ 10 /$ by use of a technique which consisted of repeated measurements of the time interval between the detection of ${ }^{17} \mathrm{C}$ and $i$ ts associated beta particle. The energy and intensity of the $\gamma$ rays of the ${ }^{17} \mathrm{C} B$ decay measured in the present study, are listed in table 2 . These $\gamma$ rays can be fitted into the known level siheme of $17_{N} / 20 /$ as it is shown in table 2 .

\begin{tabular}{rrrrr}
\hline $\begin{array}{l}E_{\gamma}(\mathrm{keV}) \\
\text { This }\end{array}$ & $\mathrm{I}_{\gamma}$ & $\begin{array}{c}E_{\boldsymbol{i}} \rightarrow E_{\mathbf{f}} \\
\text { Ref. } 20\end{array}$ \\
\hline 476.2 & $8(7)$ & $1850 \rightarrow 1375$ \\
620.0 & $18(8)$ & $2526 \rightarrow 1907$ \\
1374.8 & $100(20)$ & $1375 \rightarrow$ & 0 \\
1849.7 & $75(13)$ & $1850 \rightarrow$ & 0 \\
1906.5 & $49(13)$ & $1907 \rightarrow$ & 0 \\
\hline
\end{tabular}

Table 2 : Energy and intensity of the $\gamma$-rays measured in coincidence with the $B$ decay of ${ }^{17} \mathrm{C}$. 
III-2-2.8 decay of ${ }^{19} \mathrm{~N}$

The mass excess and excited states of this nucleus are presently known. The decay of ${ }^{19} \mathrm{~N}$ is presented here for the first time. One $\gamma$ line has been unambiguously identified in the $\gamma$ spectrum recorded in coincidence with the $\beta$ decay of ${ }^{19} \mathrm{~N}$. This $94.6 \mathrm{keV} \gamma$ ray corresponds to the transition between the known first excited state of ${ }^{19} \mathrm{o}$ and the ground state.

III-2-3. The case of ${ }^{22} 0$

The half-life of ${ }^{22} 0$ is presently known /7/ $\left(\mathrm{T}_{1 / 2}=910 \pm 350 \mathrm{~ms}\right)$. The energy and intensity of the $\gamma$ rays attributed to the $\beta$ decay of ${ }^{22} 0$ are listed in table 3 . These $\gamma$ rays fit well as transitions between known levels of ${ }^{22} \mathrm{~F} / 20 /$. Fig. 5 gives the spectra recorded in $a \simeq 10$ hours experiment. In these spectra ${ }^{22} F$ is present as daughter activity. The contaminants are essentially ${ }^{25} \mathrm{Ne}$ and its descendant ${ }^{25} \mathrm{Na}$. Their presence are understandable as ${ }^{22} \mathrm{O}$ and ${ }^{25} \mathrm{Ne}$ have almost identical $\left(\mathrm{A}^{2.5} / \mathrm{z}^{1.5}\right)$ values and are thus not discriminated by the second dipole selection. A surprising result is obtained when analysing the $637 \mathrm{keV} \gamma$ line. Indeed it appears clearly when comparing fig.5a and fig. $5 \mathrm{~b}$ that the measured integrated activity is higher during beam-off cycles than during

\begin{tabular}{|c|c|c|}
\hline$E_{\gamma}(\mathrm{keV})$ & $I_{\gamma}$ & $E_{i} \rightarrow E_{f}$ \\
\hline $\begin{array}{l}637.6 \\
918.3\end{array}$ & $\begin{array}{r}100 \\
31(9)\end{array}$ & $\begin{aligned} 660 & \rightarrow 0 \\
1570 & \rightarrow 660\end{aligned}$ \\
\hline
\end{tabular}

Table 3 : Energy and intensity of the $\gamma$ rays measured in coincidence with the $B$ decay of ${ }^{22} 0$.

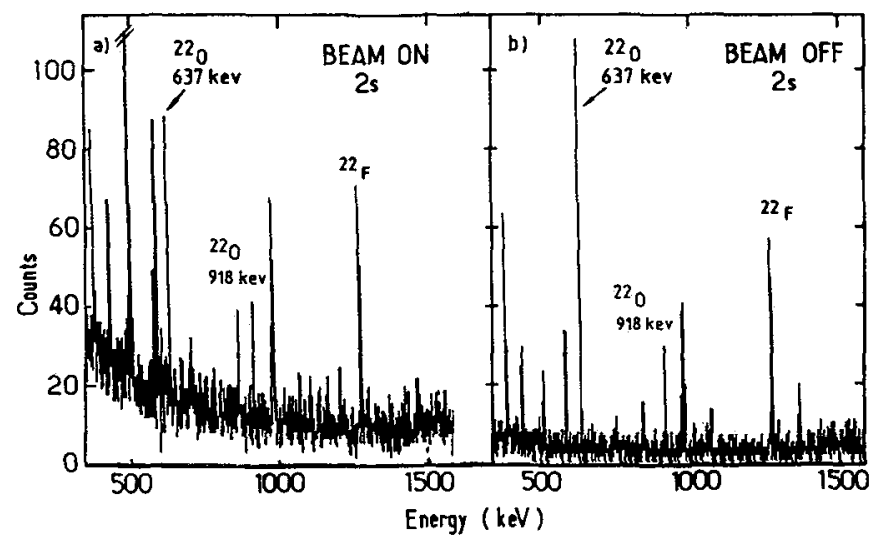

Fig. 5 $\gamma$-ray spectra measured in coincidence with $\beta$ decay of 220 .

the beam-on ones whereas the opposite, and expected, behavior is noticed for other $\gamma$ lines. The $637 \mathrm{keV} \gamma$-ray activity is plotted in fig. $6 \mathrm{a}$ as a function of time. Here again anomalous variations are observed since the increase-decrease of the activity are delayed. As an example of expected evolution, fig. $6 \mathrm{~b}$ provides the count-rate measured on the $90 \mathrm{keV} \gamma$ line emitted in coincidence with the $\beta$ decay of the contaminant ${ }^{25} \mathrm{Ne}$. Detailed analysis of the experimental conditions allow us to conclude that this behavior is likely interpreted, with a high level of confidence, as due 
to the existence of an isomeric state in ${ }^{22} 0$ which decay toward the $0^{+}$ground state with an half-life between 0.5 s and $1 \mathrm{~s}$. Direct observation of isomers cannot be done in the present experiment since only $\gamma$ spectra measured in coincidence with $\beta$ are recorded. ${ }^{22} 0$ could be a semi-magic nucleus, 1 ike ${ }^{68} \mathrm{Ni}$ and ${ }^{90} \mathrm{Zr}$, with a proton closed shell and a neutron half-closed shell. Both nuclei ${ }^{68} \mathrm{Ni}$ and ${ }^{90} \mathrm{Zr}$ show a $0^{+}$first excited state which corresponds to a deformed isomeric state /21/. The existence of an isomeric state in a neutron rich sd nucleus with a quite long half-life attracts particular interest in terms of nuclear structure. Further experiments are needed to confirm (or avoid) this presumption and are planned in the near future.

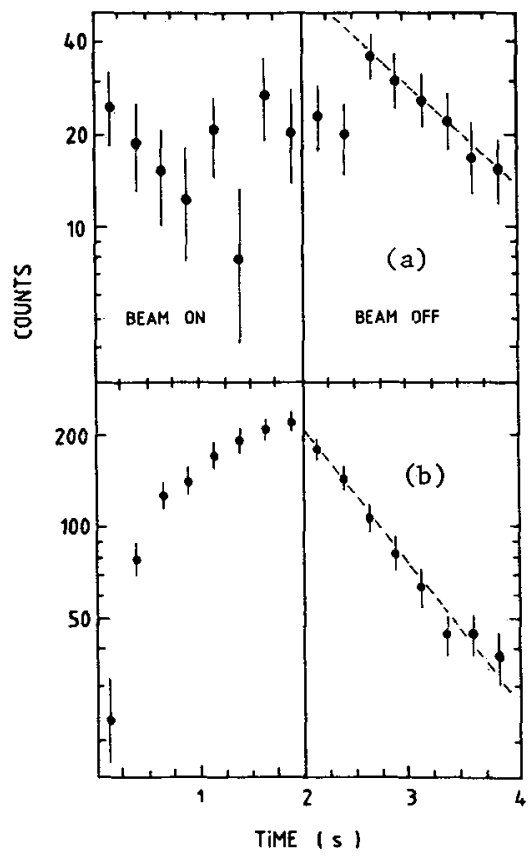

Fig. 6 a) Evolution of the count-rate of the ${ }^{22} \mathrm{O}$ $637 \mathrm{keV} \gamma$ line during beam on and beam off cycles b) the same as (a) for the $90 \mathrm{keV}$ of $25 \mathrm{Ne}$

III-2-4. $\beta$ decay of ${ }^{24} \mathrm{~F}$

One $\gamma$ Iine has been identified. This $1982 \mathrm{keV} \gamma$ line corresponds to the transition to the ground state of the known first excited leve 1 of $24 \mathrm{Ne} / 20 /$. Shell mode 1 calculations have been done in ref. 15 for ${ }^{24} \mathrm{~F}$. Two predictions are given since there is an ambiguity on the spin ground state. On the one hand, the measured half-life agrees with a $2^{+}$ground state assumption. On the other hand only the $1982 \mathrm{keV}$ line is observed while $24 \mathrm{~F}$ is predicted to proceed dominantly to the 1981 and $3867 \mathrm{keV}$ levels of $24 \mathrm{Ne}$. No transition between these 2 levels has been observed (with $R=I(1886 \mathrm{keV}) / \mathrm{I}(1981 \mathrm{keV})$ $<5 \%$ ) whereas ref. 15 would predict $R \simeq 33 \%$ and $R \simeq 10 \%$ with the assumption of $2^{+}$and $3^{+}$ground state respectively.

III-2-5. B decay of ${ }^{26} \mathrm{Ne}$

One $\gamma$ line has been identified as following the decay of ${ }^{26} \mathrm{Ne}$. This $233.5 \mathrm{keV}$ line, would correspond to the transition to the ground state of the known $241 \pm 31$ level in $26 \mathrm{Na}$. Due to the strong activity measured for the daughter nucleus the decay of $26_{\mathrm{Ne}}$ is likely to occur toward low excited states of $26_{\mathrm{Na}}$. This result is consistent with predictions of ref. 15 which calculate $90 \%$ feeding of the first $26_{\mathrm{Na}}$ level, if one assumes that the excitation energy of this level is lower than $45 \mathrm{kev}$, our experimental threshold. 
III-2- B decay of ${ }^{33-34}$ AI i.sotopes

No $\gamma$ a -ivity could be associated to the $\beta$ decay of ${ }^{33} \mathrm{Al}$. In the recorded spectrum the most important observed $\gamma$ rays belong to $33-34 \mathrm{Si}$ and $36 \mathrm{P}$. The presence of $33 \mathrm{Si}$ undoubtly indicate that $33 \mathrm{Al}$ was produced and transmitted by the LISE line. The $33 \mathrm{Al}$ decay is likely not observed due to the strong direct feeding of the ground state in $33 \mathrm{si}$. This result is in agreement with the ref. 15 which predicts that $95 \%$ of the $B$ decay populate the ground state or neutron unbound states.

One $\gamma$-ray has been identified in the $\beta$ decay of $34 \mathrm{Al}$. This $123.9 \mathrm{keV}$ line does not fit into the recently studied level scheme of $34 \mathrm{Si} / 22,23 /$.

$$
\text { III-2-7, B decay of }{ }^{35-36} \mathrm{Si} \text { isotopes }
$$

Seven $\gamma$ lines have been attributed to the $\beta$ decay of ${ }^{35} \mathrm{Si}$ (table 4 ). Only $3 \gamma$ rays can be fitted into the recently measured $35 \mathrm{P}$ level scheme $/ 24 /$. These lines correspond to transition toward the ground state of the lowest excited states in $35 \mathrm{P}$. From table 4 ,

\begin{tabular}{|c|c|c|}
\hline $\begin{array}{r}E_{\gamma}(\mathrm{keV}) \\
\text { This }\end{array}$ & ${ }_{\text {work }}^{\mathrm{I}_{\gamma}}$ & $\begin{aligned} E_{i} & \rightarrow E_{f} \\
\text { (Ref. } 24 & + \text { this work } \\
& +\end{aligned}$ \\
\hline $\begin{array}{l}242.3 \\
393.3 \\
634.3\end{array}$ & $\begin{array}{ll}66 & (4) \\
42 & (4) \\
17 & (4)\end{array}$ & $\begin{array}{l}4099^{+} \rightarrow 3857 \\
4493 \rightarrow 4099^{+} \\
4493 \rightarrow 3857\end{array}$ \\
\hline 1993.4 & $28(5)$ & - \\
\hline 2386.2 & $92(9)$ & $2386 \rightarrow$ \\
\hline 3857.5 & $71(8)$ & $3857 \rightarrow$ \\
\hline 4099.0 & $100(8)$ & $4099^{+} \rightarrow$ \\
\hline
\end{tabular}

Table 4 : Energy and intensity of the $\gamma$ rays measured in coincidence with the decay of ${ }^{35} \mathrm{Si}$.

one can see that the $4099 \mathrm{keV}$ line, cannot be fitted into the proposed ${ }^{35} \mathrm{P}$ levels. As the most intense, this transition must proceed from a new level at $4099 \mathrm{keV}$ to the ground state of $35 \mathrm{P}$. The $242 \mathrm{keV}$ line is thus a transition between this state and the previously known level at $3857 \mathrm{keV}$.

The energy and intensity of the $\gamma 1$ ines observed in the decay of ${ }^{36} \mathrm{Si}$ are 1 isted in table 5. There is some uncertainty in the litterature over the energy of the first

\begin{tabular}{|c|c|c|}
\hline $\begin{array}{r}\mathrm{E}_{\gamma}(\mathrm{keV}) \\
\text { This }\end{array}$ & $\underset{\text { work }}{I_{\gamma}}$ & $\begin{array}{c}E_{i} \rightarrow E_{f} \\
(\text { Refs. 25, 22) }\end{array}$ \\
\hline $\begin{array}{r}175.7 \\
251.0 \\
425.8 \\
878.9 \\
922.3 \\
1855.3\end{array}$ & $\begin{array}{r}100(5) \\
97(5) \\
52(5) \\
50(6) \\
17(5) \\
46(8)\end{array}$ & $\begin{array}{l}426 \rightarrow 251 \\
251 \rightarrow 0 \\
426 \rightarrow 0\end{array}$ \\
\hline
\end{tabular}

Table 5 : Energy and intensity of the $\gamma$ rays measured in coincidence with the decay of ${ }^{36} \mathrm{Si}$

excited state in ${ }^{36} \mathrm{P}$. Ref. 25 reported a state at $(252 \pm 10) \mathrm{keV}$ while ref. 22 reported a state at $(450 \pm 22) \mathrm{keV}$. The presence in the spectrum of the 3 first lines as shown in table 5 (the $176 \mathrm{keV}$ line being exactly the difference between the two followings) strongly supports the existence of both the $251 \mathrm{keV}$ and $426 \mathrm{keV}$ levels in $36 \mathrm{P}$.

\section{III-2-8 $\beta$ decay of phosphorus isotopes}

The last known phosphorus isotope is ${ }^{36} \mathrm{P}$, studied by Hill et a1. /26/. They only observed three $\gamma$ rays. Compared to their results, 18 new lines were observed in the present study. Much information is available on leve1s on $36 \mathrm{~s}$ and 14 excited levels up to $7.12 \mathrm{MeV}$ are presently known /20/. Most of the observed $\gamma$ lines can be fitted into the proposed decay scheme. Four new levels are likely present. A more complete decay scheme of $36 \mathrm{p}$ and new $36 \mathrm{~S}$ levels will be published later. 


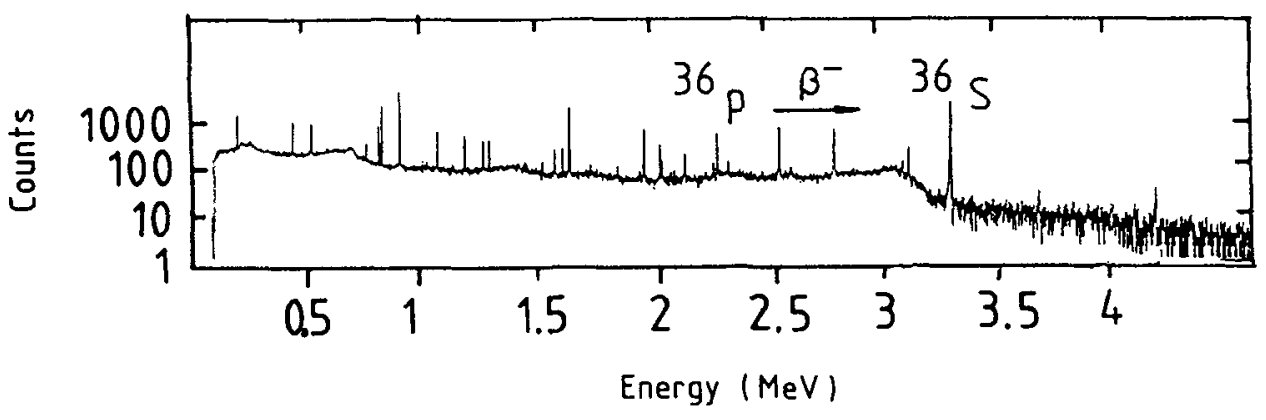

The energy and intensity of the $\gamma$ lines attributed to the $\beta$ decay of ${ }^{37} P$ are 1 isted in table 6 . The contaminant nuclei at the 1 to. $5 \%$ level are ${ }^{36} \mathrm{P}$ and ${ }^{39} \mathrm{~S}$. The $Y_{1}=647 \mathrm{keV}$ and $\gamma_{2}=752 \mathrm{keV}$ transitions correspond to the feeding of the already known first excited states in $37 \mathrm{~s} / 27 /$. A peak observed at $2230 \mathrm{keV}$ corresponds to the sum of the 646 and $1583 \mathrm{keV}$ gammas ; its intensity fits to the calculated one assuming that the high efficiency Ge detector worked as a total sum detector for the cascade $1582 \rightarrow 646$. This establishes a new level at $2229 \mathrm{keV}$ in $37 \mathrm{~S}$.

\begin{tabular}{|c|c|c|}
\hline $\begin{array}{r}\mathrm{E}_{\gamma}(\mathrm{keV}) \\
\text { This }\end{array}$ & $\overline{\mathbf{I}}_{\gamma}$ & $\begin{aligned} E_{i} & \rightarrow E_{f} \\
(\operatorname{Ref} .27 & \left.+ \text { this work }^{+}\right)\end{aligned}$ \\
\hline $\begin{array}{r}646.3 \\
751.3 \\
1582.9 \\
2100.8 \\
2254.0\end{array}$ & $\begin{aligned} 100 & (3) \\
7 & (1) \\
75 & (5) \\
4 & (1) \\
6 & (1)\end{aligned}$ & $\begin{array}{rrr}646 & \rightarrow & 0 \\
1397 & \rightarrow & 646 \\
2229^{+} & \rightarrow & 646 \\
- & -\end{array}$ \\
\hline
\end{tabular}

Table 6 : Energy and intensity of the $\gamma$ rays measured in coincidence with the decay of $37 \mathrm{P}$.

Two lines have been identified in the $\beta$ decay of ${ }^{38} \mathrm{P}$ (table 7 ). Excited levels of $38 \mathrm{~S}$ have been recently investigated $/ 28 /$. Only the $1293 \mathrm{keV}$ line can be fitted into the proposed level scheme.

\begin{tabular}{rrr}
\hline $\begin{array}{r}E_{\gamma}(\mathrm{keV}) \\
\text { This work }\end{array}$ & $\begin{array}{c}\mathrm{E}_{\boldsymbol{i}} \rightarrow \mathrm{E}_{\mathrm{f}} \\
\text { (Ref. 28) }\end{array}$ \\
\hline $\begin{array}{r}1293.3 \\
3517.0\end{array}$ & $\begin{array}{r}100(3) \\
\text { (3) }\end{array}$ & $1293 \rightarrow 0$ \\
\hline
\end{tabular}

Table 7 : Energy and intensity of the $\gamma$ rays measured in coincidence with the decay of $38 \mathrm{p}$.

III-2-9 3 decay of ${ }^{40} \mathrm{~s}$

Four $\gamma$ rays have been attributed to the decay of ${ }^{40} \mathrm{~S}$ (table 8 ). Excited levels in $40 \mathrm{Cl}$ have been recently studied via charge exchange reaction $/ 29 /$. The 212 and $433 \mathrm{keV} 1$ ines can be fitted quite well into this $40 \mathrm{Cl}$ level scheme as it is tentatively shown in table 8 . The measured relative intensities indicate that no $B$ feeding of the $212 \mathrm{keV}$ level is likely to occur.

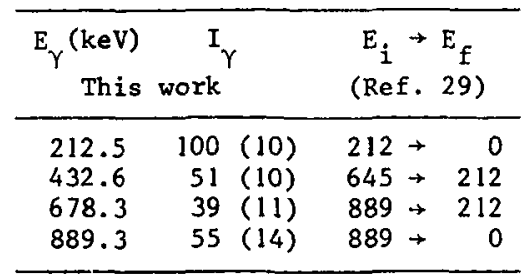

Table 8 : Energy and intensity of the $\gamma$ rays measured in coincidence with the decay of $40 \mathrm{~S}$. 
IV - CONCLUSION

This paper reports on some recent studies of light neutron rich nuclei performed in the GANIL energy domain. From an experimental point of view, the accent is especially given on a new method which allows to use the magnetic spectrometer LISE as an isotopic separator by the adjunction of an intermediate energy degrader between the 2 dipoles. New $B$ decay half-lives and $\beta-\gamma$ spectroscopies are presented. The predictive power of different models is examined. Concerning the half-lives, the predictions of Wildenthal et al. give the best agreement but they are unfortunately restricted to the sd shell nuclei. As far as decay probabilities and excited levels are concerned the comparisons of the existing predictions in the studied region with the experimental results do not allow a definite conclusion in the present stage of development. A close collaborative interplay between experiment and theory is needed to solve nuclear structure problems.

\section{REFERENCES}

/ I/ M. Langevin, et a1., Phys. Lett. 150B (1985),71.

/ 2/ D. Guillemaud-Mueller, et a1., 2. Phys. A322 (1985) 415.

/ 3/ D. Guerraud, presented at the XXIII International Winter Meeting on Nuclear Physics (Bormio, 1985).

/ $4 / \mathrm{F}$. Pougheon, presented at the XXIV International Winter Meeting on Nuclear Physics (Bormio, 1986)

/ 5/ T.J.M. Symons, et al., Phys. Rev. Lett. 42 (1979) 40.

/ 6/ G.D. Westfall, et al., Phys. Rev. Lett. 43 (1979) 1859.

/ $7 /$ M.J. Murphy, et al., Phys. Rev. Lett. 49 (1982) 455.

/ 8/ M. Langevin, et al, Proceedings Conf. on Instrumentation For Ion Nucleon Research Oak-Ridge (1984)

/ 9/ L.H. Harwood, et a1., Nucl. Instr. and Meth. 186 (1981) 435.

$110 /$ M.S. Curtin, et al., Phys. Rev. Lett. 56 (1986) 34.

$/ 11 /$ J.P. Dufour, et a1., to be published in Nucl. Instr. and Meth.

/12/ J.P. Dufour, et al., Z. Phys. A319 (1984) 237.

/13/ A. Fleury, et al., Nuc1. Instr. and Meth. B10/11 (1985) 369.

$/ 14 / \mathrm{F}$. Hubert, et al., Ann. Phys. (Paris) $5 \mathrm{~S}$ (1980) 1.

$/ 15 /$ B. H. Wildenthal, et al., Phys. Rev. C28 (1983) 1343.

/16/ C.L. Woods, Nucl. Phys. A451 (1986) 413.

117/ Chart of Nuclides (1984) Compiled by Y. Yoshizawa et al.

R. Takahashi, et al., At. Data and Nucl. Data Tables 12 (1973) 101 .

$/ 18 / \mathrm{T}$. Kondoh, et al., Prog. Theor. Phys. 74 (1985) 708.

/19/ H.V. Klapdor, et al., At. Data and Nucl. Data Tables 31 (1984) 81.

$120 /$ Tables of Isotopes, edited by C.M. Lederer and V.S. Shirley, J. Wiley, New York, 1978.

121/ M. Bernas, et a1., J. Physique Lett. 45 (1984) L-851

$122 /$ W. A. Meyer, et al., Z. Phys.A319 (1984) 287.

/23/ L.K. Fifield, et al., Nucl. Phys. A440 (1985) 531.

/24/ S.Kahn, et al., Phys. Lett. 156B (1985) 155.

/25/ P.V. Drumm, et al, Nucl. Phys. A44] (1985) 95.

/26/ J.C. Hill, et a1., Phys. Rev. C25 (1982) 3104.

/27/ C.E. Thorn, et al., Phys. Rev. C30 (1984) 1442.

/28/ V.J. Davis, et al. Phys. Rev. C32 (1985) 713.

/29/ L.K. Fifield, et a1., Nucl. Phys. A417 (1984) 534. 